\title{
Analysis of Radial Artery Catheter Placement by Respiratory Therapists Using Ultrasound Guidance
}

\author{
Andrew G Miller RRT-ACCS, Jhaymie L Cappiello RRT-ACCS, \\ Michael A Gentile RRT FAARC, Andrew M Almond RRT, \\ Janice J Thalman MHS RRT FAARC, and Neil R MacIntyre MD FAARC
}

\begin{abstract}
BACKGROUND: The use of ultrasound (US) guidance for radial artery cannulation has been shown to improve first attempt success rate, reduce time to successful cannulation, and reduce complications. We sought to determine whether properly trained respiratory therapists (RTs) could utilize US guidance for the placement of radial artery catheters. Primary outcome measurements were successful cannulation and first attempt success rate. Secondary outcomes included the effect of systolic blood pressure, prior attempts, palpable pulse strength, and gender in relation to USguided radial artery cannulation success rates. METHODS: RTs certified in arterial catheter insertion were trained in radial artery catheterization using US by emergency medicine physicians. Subjects were enrolled based on the need for an arterial catheter placement. The catheters and US devices used were standardized. Data recorded included pulse strength, systolic and diastolic blood pressure, number of attempts, and successful/unsuccessful artery cannulation. All catheterization attempts were performed according to institutional policy and procedure. RESULTS: One hundred twenty-two radial artery catheter insertion attempts were made between December of 2008 and October of 2011, in patients in whom the treating physician requested RT radial artery cannulation. The overall success rate was $\mathbf{8 6 . 1 \%}$, whereas the first attempt success rate was $63.1 \%$. There was no difference found between the overall mean success rate for weak or absent pulses, age, systolic blood pressure, gender, or prior attempts. Conclusion: RTs can effectively utilize US technology to place radial artery catheters. Systolic blood pressure, prior attempts, and gender are not reliable predictors of success for US-guided radial artery cannulation. Training on the use of US should be strongly encouraged for all practitioners who place radial artery catheters. Key words: radial artery cannulation; ultrasound guidance; respiratory therapist; radial artery catheter. [Respir Care 2014;59(12):1813-1816. () 2014 Daedalus Enterprises]
\end{abstract}

\section{Introduction}

Arterial catheters are commonly placed in critically ill patients for continuous blood pressure monitoring, fre-

\footnotetext{
Mr Miller, Mr Cappiello, Mr Almond, and Ms Thalman are affiliated with Respiratory Care Services; Mr Gentile is affiliated with the Division of Critical Care; and Dr MacIntyre is affiliated with the Division of Pulmonary and Critical Care, Duke University Medical Center, Durham, North Carolina.
}

Mr Miller presented a portion of this research at the AARC Congress 2011, held November 5-8, 2011, in Tampa, Florida.

This study was supported by departmental funding from Duke University Medical Center. The authors have disclosed no conflicts of interest. quent arterial blood gas analysis, or frequent blood sampling for diagnostic testing. The radial artery is often the first choice for arterial catheter placement due to its superficial location and the presence of collateral blood supply to the hand via the ulnar artery. ${ }^{1}$ Currently utilized percutaneous techniques for arterial cannulation include: puncturing the vessel and then advancing the catheter over a guidewire (modified Seldinger technique), or puncturing

\footnotetext{
Correspondence: Andrew G Miller RRT-ACCS, Post Office Box 3911 , Respiratory Care Services, Duke University Medical Center, 2301 Erwin Road, Durham, NC 27710. Email: Andrew.g.miller@duke.edu.
}

DOI: $10.4187 /$ respcare.02905 


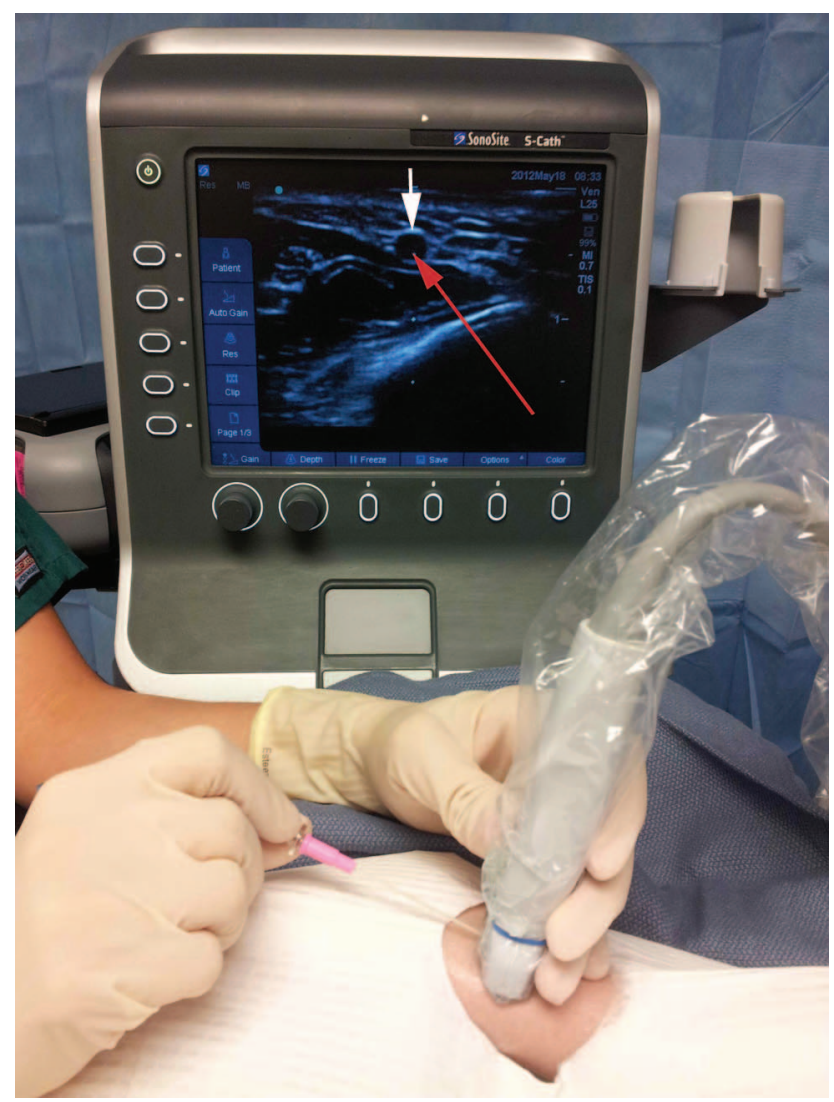

Fig. 1. Example of radial artery being cannulated. The red arrow corresponds to the center of the radial artery. The white arrow corresponds to the path of the needle as it approaches the artery when properly centered. The ultrasound probe is fully prepped for use with an adequate sterile field established.

the vessel and then directly advancing the catheter into the artery.

The traditional method for locating the radial artery is via palpation of the pulse in conjunction with anatomic landmarks. However, the location of the artery may be variant in up to $30 \%$ of patients and thus difficult to find. ${ }^{2}$ Moreover, in patients with severe hypotension, morbid

See the Related Editorial on Page 1946

obesity, arterial scarring, edema, and atherosclerosis, locating the artery via palpation may be difficult or impossible. Additional difficulties encountered when attempting the placement of radial artery catheters include: inability to thread the wire, hematoma formation, and arterial spasm. More recently, imaging techniques have been developed to facilitate catheter placement. One imaging technique that is portable, easy to use (after proper training), and readily available is direct vessel visualization with 2-dimensional ultrasound (US) guidance (Fig. 1). 3,4

\section{QUICK LOOK}

\section{Current knowledge}

Ultrasound guidance has been shown to improve successful radial artery cannulation in critical care. Complications are fewer, time to successful cannulation is reduced, and first attempt success is improved. These findings have predominantly been accomplished by physicians.

\section{What this paper contributes to our knowledge}

Respiratory therapists can effectively use ultrasound to place radial artery catheters with success rates similar to those published for physicians. Gender, systolic blood pressure, and prior attempts were not predictive of success.

In 2008, we began a respiratory therapist (RT) training program on the use of US to facilitate radial artery catheter placement. Training included: US equipment operation, identification of the radial artery, demonstrations of the transverse and longitudinal methods of visualizing the artery, proper sterile technique, and proper hand technique to prevent probe movement during attempts. The purpose of this report is to describe our initial experience with RTs using US guidance to place radial arterial catheters.).

\section{Methods}

Consecutive subjects from December 2008 to October 2011 (35 months) in whom radial artery catheter placement using US guidance was attempted were studied. These subjects were mostly emergency department patients in whom the physician requested RT radial artery cannulation. Ten RTs participated in this service with a wide range of experience placing radial artery catheters $(2-30 \mathrm{y})$. The decision to use US guidance was at the discretion of the RT. Data on US use was tracked as part of ongoing departmental quality assurance evaluations of RT performance with radial artery cannulation. Institutional review board approval was obtained for the review of the recorded data.

All data were recorded by the RT performing the cannulation attempt and included: age, strength of pulse, systolic blood pressure, number of cannulation attempts, gender, and ultimate successful or unsuccessful artery catheter placement. Pulse strength was recorded as absent, weak, or normal by the RT before initial cannulation attempt. Systolic blood pressure was the most recent blood pressure recorded by automatic or manual cuff before US-guided cannulation attempt. Hypotension was defined as a sys- 


\section{Ultrasound-Guided Radial Artery Catheter Placement by RTs}

Table 1. Radial Artery Cannulation Success Using Ultrasound Guidance by Respiratory Therapists

\begin{tabular}{|c|c|c|c|c|c|}
\hline & $n$ & $\begin{array}{c}\text { Overall } \\
\text { Success Rate } \\
(\%)\end{array}$ & $P$ & $\begin{array}{c}\text { First Attempt } \\
(\%)\end{array}$ & $P$ \\
\hline \multicolumn{6}{|l|}{ Age* } \\
\hline $60 \mathrm{y}$ & 57 & 86.0 & .80 & 64.9 & .70 \\
\hline$\leq 60 \mathrm{y}$ & 56 & 83.9 & & 60.7 & \\
\hline \multicolumn{6}{|l|}{ Gender } \\
\hline Male & 65 & 87.7 & .61 & 60.0 & .46 \\
\hline Female & 57 & 84.2 & & 66.7 & \\
\hline \multicolumn{6}{|l|}{ Blood pressure } \\
\hline Hypotensive & 60 & 88.3 & .60 & 60.0 & .32 \\
\hline Nonhypotensive & 62 & 83.9 & & 62.9 & \\
\hline \multicolumn{6}{|c|}{$\begin{array}{l}P \text { values were computed using Fisher exact test for overall success rate and first attempt } \\
\text { success rate for age, gender, and hypotension. } \\
\text { * Data on age were not recorded for } 9 \text { subjects. } \\
\text { Hypotensive }=\text { systolic blood pressure }<90 \mathrm{~mm} \mathrm{Hg}\end{array}$} \\
\hline
\end{tabular}

tolic blood pressure $<90 \mathrm{~mm} \mathrm{Hg}$. As a comparison, the success rate for our RT radial artery cannulation without US guidance during all of 2011 was calculated. Fisher exact test and unpaired $t$ test were performed where appropriate. A $P$ value $<.05$ was considered statistically significant.

\section{Results}

Over the study period, 122 US-guided radial artery cannulations were analyzed. One hundred twenty-one cannulation attempts were in the emergency department and 1 in the ICU. The subject population had an average age of $59.6 \pm 16.0$ y, and 53.3\% $(n=65)$ were males. Data on age was not recorded for 9 subjects. The overall US-guided success rate was $86.1 \%$ (105/122). First attempt success rate was $63.1 \%$ (77/122). Importantly, in subjects with an initial unsuccessful cannulation, the ultimate success rate was comparable to those subjects with successful first attempts $(86.1 \%$ vs $86.0 \%, P>.99)$. As a comparison, the RT success rate for radial artery cannulation throughout the entire institution for all of 2011 without US guidance was $77.8 \%(624 / 802)(P=.04$ when compared with the overall US success rate we observed).

There were no statistically significant differences in either first attempt success versus failure or ultimate success versus failure related to age, gender, or presence of hypotension (Table 1). There was no statistically significant difference in overall success rate or first attempt success rate based upon pulse strength or systolic blood pressure (Table 2). Of note is that in 3 subjects with no detectable blood pressure, catheters were successfully placed in 2 .
Table 2. Radial Artery Cannulation Success Using Ultrasound Guidance by Respiratory Therapists Based on Subjective Pulse Strength and Systolic Blood Pressure

\begin{tabular}{|c|c|c|c|c|c|}
\hline & $n$ & $\begin{array}{c}\text { Overall } \\
\text { Success Rate } \\
(\%)\end{array}$ & $P$ & $\begin{array}{l}\text { First Attempt } \\
\qquad(\%)\end{array}$ & $P$ \\
\hline \multicolumn{5}{|l|}{ Pulse strength } & \\
\hline Absent & 54 & 79.6 & .054 & 53.7 & .13 \\
\hline Weak & 47 & 87.2 & & 68.1 & \\
\hline Normal & 21 & 100 & & 76.2 & \\
\hline \multicolumn{6}{|l|}{ Blood pressure } \\
\hline Undetectable* & 3 & 66.7 & .73 & 66.7 & .53 \\
\hline $60 \mathrm{~mm} \mathrm{Hg}$ & 11 & 90.9 & & 45.5 & \\
\hline $60-90 \mathrm{~mm} \mathrm{Hg}$ & 46 & 89.1 & & 67.4 & \\
\hline $90-120 \mathrm{~mm} \mathrm{Hg}$ & 32 & 81.3 & & 59.4 & \\
\hline $120 \mathrm{~mm} \mathrm{Hg}$ & 30 & 86.7 & & 66.7 & \\
\hline \multicolumn{6}{|c|}{$\begin{array}{l}P \text { values were computed using Fisher exact test for overall success rate and first attempt } \\
\text { success rate for pulse strength and discrete blood pressure ranges. } \\
* \text { S Subjects with undetectable blood pressure were excluded from statistical analysis. }\end{array}$} \\
\hline
\end{tabular}

\section{Discussion}

Our results demonstrate that properly trained RTs can insert radial artery catheters via US guidance with an overall success rate better than our routine non-US techniques ( $86.1 \%$ vs $77.8 \%$, respectively). Moreover, our first attempt success rate with US was equal to or better than those reported by other ICU clinicians (including physicians) in a systematic review (our observed first attempt success rate was $63 \%$ vs $43 \%$ in the pooled results of the review). In that systemic review, the authors also concluded that US guidance significantly improves first attempt success rate versus non-US technique, with a number needed to treat of six. ${ }^{5}$ A narrative review by the same group summarized the results of three randomized, controlled trials and also concluded US guidance resulted in fewer attempts and less time for successful catheter placement than non-US techniques. ${ }^{6}$

Higher first attempt success rates using US guidance should translate into better outcomes. For example, catheter-related infections should decrease, and the likelihood of nerve damage should decrease with a reduction in cannulation attempts and higher overall and first attempt success rates. Indeed, a number of studies have shown that US guidance has been proven to reduce complications and increase success rates for radial artery catheter placement. 3,5,7-10

Our study is limited because we did not systematically record the US technique used (transverse, longitudinal, or static), the subject's body habitus, or the indication for arterial line placement. In addition, our assessment of pulse strength was subjective and intrapractitioner variability is possible. Finally, the decision to use US to assist in the 


\section{Ultrasound-Guided Radial Artery Catheter Placement by RTs}

cannulation attempt was determined by the RT placing the arterial catheter and was likely biased toward using US in more challenging patients where difficulty was anticipated or had been encountered by another clinician. This is supported by the fact that $82.7 \%$ of our US cannulation attempts were done in subjects with a weak or absent radial pulse (Table 2).

Although US guidance could be considered for most clinical settings, it should especially be considered in patients without palpable radial pulses, coagulopathy or abnormal clotting factors, severe hypotension, or when the radial artery is the only site available. The use of US may also be useful in initial training of healthcare providers in radial artery catheter placement. Guidance by US is the standard of care for placement of central venous catheters; in the future, US guidance may become the standard of care for radial artery cannulation as well.

In conclusion, US guidance can be utilized effectively by RTs. Systolic blood pressure, prior attempts, and gender are not reliable predictors of success for US-guided radial artery cannulation. Training on the use of US should be strongly encouraged for all practitioners who currently place radial artery catheters.

\section{ACKNOWLEDGMENTS}

We thank Tony Huang MD for his review of the statistical methods used.

\section{REFERENCES}

1. O'Grady NP, Alexander M, Burns LA, Dellinger EP, Garland J, Heard SO, et al. Guidelines for prevention of intravascular catheterrelated infections, 2011. Clin Infect Dis 2011;52(9):e162-e193.

2. Brzezinski M, Luisetti T, London MJ. Radial artery cannulation: a comprehensive review of recent anatomic and physiologic investigations. Anesth Analg 2009;109(6):1763-1781.

3. Levin PD, Sheinin O, Gozal Y. Use of ultrasound guidance in the insertion of radial artery catheters. Crit Care Med 2003;31(2):481484.

4. Brannam L, Blaivas M, Lyon M, Flake M. Emergency nurses' utilization of ultrasound guidance for placement of peripheral intravenous lines in difficult-access patients. Acad Emerg Med 2004;11(12): 1361-1363.

5. Shiloh AL, Savel RH, Paulin LM, Eisen LA. Ultrasound-guided catheterization of the radial artery: a systematic review and metaanalysis of randomized controlled trials. Chest 2011;139(3):524-529.

6. Shiloh AL, Eisen LA. Ultrasound-guided arterial catheterization: a narrative review. Intensive Care Med 2010;36(2):214-221.

7. Shiver S, Blaivas M, Lyon M. A prospective comparison of ultrasound-guided and blindly placed radial arterial catheters. Acad Emerg Med 2006;13(12):1275-1279.

8. Miller A, Cappiello J, Gentile M, Almond A, Thalman J, MacIntyre $\mathrm{N}$. Radial artery catheterization by respiratory care practitioners with ultrasound guidance [abstract]. Respir Care 2009;54(10):1547.

9. Sandhu NS, Patel B. Use of ultrasonography as a rescue technique for failed radial artery cannulation. J Clin Anesth 2006;18(2):138141.

10. Schwemmer U, Arzet HA, Trautner H, Rauch S, Roewer N, Greim CA. Ultrasound-guided arterial cannulation in infants improves success rate. Eur J Anaesthesiol 2006;23(6):476-480.

This article is approved for Continuing Respiratory Care Education credit. For information and to obtain your CRCE

(free to AARC members) visit

www.rcjournal.com

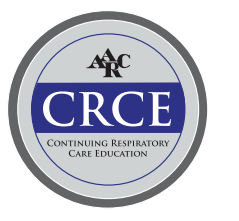

